\title{
Tinjauan Kebutuhan Air Irigasi Saluran Sekunder Taroang Daerah Irigasi Kelara
}

\author{
Muhammad Taufik Iqbal ${ }^{1, a}$ dan Zulvyah Faisal ${ }^{1, b}$ \\ ${ }^{1}$ Jurusan Teknik Sipil, Politeknik Negeri Ujung Pandang, Jalan Perintis Kemerdekaan KM.10, Makassar, 90245, Indonesia \\ a muhtaufikiqbal@poliupg.ac.id \\ bulvyahfaisal@poliupg.ac.id
}

\begin{abstract}
The purpose of the research is the determination of Irrigation water requirement based on primer datas collecting and analysis factors of land preparation, plant growth, determination of water loss due to percolation. Irrigation water requirement depends from various factors in the preparation of the land, plant growth, determination of water loss due to percolation, the determination of the replacement of water and rain layer effectively. The availability of irrigation water is calculated based on discharge data retrieval on the Taroang Secondary channel. which then processed to obtain the final result of the availability of water in the channel. Results of the study shown that needs water to irrigate an area of secondary channels Taroang covering an area of $2,140 \mathrm{Ha}$ as much 39.11 $\mathrm{m}^{3} / \mathrm{s}$. While the availability of water that goes into the secondary channel taroang where discharge a minimum of $0.12 \mathrm{~m}^{3} / \mathrm{s}$ and the maximum discharge of $0.31 \mathrm{~m}^{3} / \mathrm{s}$.
\end{abstract}

Keywords-Irrigation water requirement; discharge.

\begin{abstract}
Abstrak- Tujuan dari penelitian ini adalah penentuan kebutuhan air irigasi berdasarkan primer data pengumpulan dan analisis faktor persiapan lahan, pertumbuhan tanaman, penentuan kehilangan air karena perkolasi. Kebutuhan air irigasi tergantung dari berbagai faktor dalam persiapan lahan, pertumbuhan tanaman, penentuan kehilangan air karena perkolasi penentuan penggantian lapisan air dan hujan secara efektif. Ketersediaan air irigasi dihitung berdasarkan pengambilan data debit pada saluran menengah Taroang. yang kemudian diproses untuk mendapatkan hasil akhir dari ketersediaan air di saluran. Hasil penelitian menunjukkan bahwa kebutuhan air untuk mengairi wilayah sekunder saluran Taroang meliputi wilayah seluas 2,140 Ha sebanyak $39.11 \mathrm{~m} 3 / \mathrm{s}$. Sementara ketersediaan air yang masuk ke dalam taroang SS dimana discharge minimum $0,12 \mathrm{m3} / \mathrm{s}$ dan pelaksanaan maksimum $0.31 \mathrm{~m} 3 / \mathrm{s}$.
\end{abstract}

Kata Kunci-Kebutuhan Air Irigasi; Debit

\section{Pendahuluan}

Bangunan air didirikan untuk mengalirkan air dan menyuplai kebutuhan irigasi di persawahan. Data yang lengkap terkait dengan analisa kebutuhan air dibutuhkan untuk merencakan besar debit pada saluran primer, saluran sekunder, dan saluran tersier [1].

Kunci utama dalam meningkatkan kesejahteraan petani yaitu dengan memperbaiki infrastuktur pengairan. Apabila infrastuktur pengairan berfungsi secara optimal, maka akan menambah kesejahteraan petani. Oleh karena itu kondisi fisik infrastuktur harus dijaga agar tetap berfungsi dan terawat [2]. Bangunan air didirikan untuk mengalirkan air dan menyuplai kebutuhan irigasi di persawahan. Data yang lengkap terkait dengan analisa kebutuhan air dibutuhkan untuk merencakan besar debit pada saluran primer, saluran sekunder, dan saluran tersier. Kunci utama dalam meningkatkan kesejahteraan petani yaitu dengan memperbaiki infrastuktur pengairan.

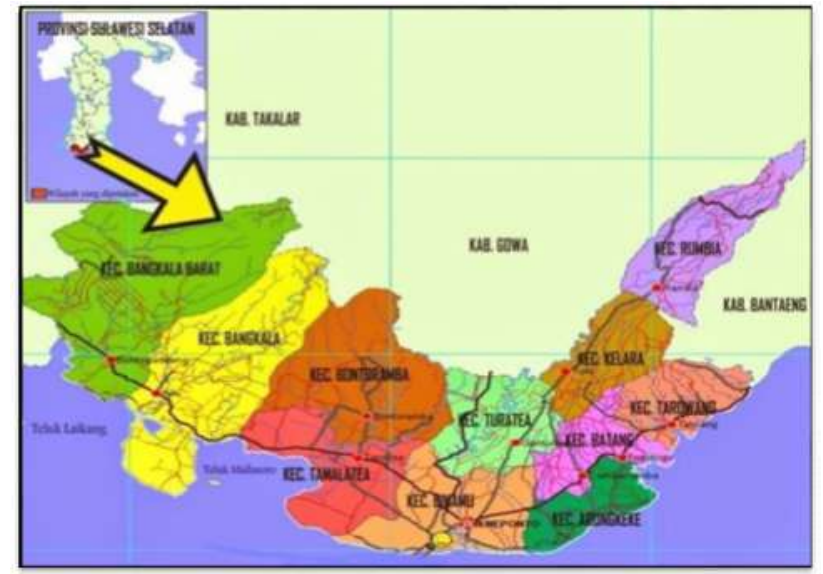

Gambar 1. Lokasi Penelitian

Daerah irigasi (DI) Kelara yang direncanakan seluas 7.004 Ha tidak dapat teraliri sepenuhnya selama musim kemarau. Saat ini DI. Kelara telah ada jaringan irigasi yang disuplai oleh 2 bendung, yaitu bendung Kelara dan 
bendung Karalloe [1], [3]-[5]. Saluran Sekunder (SS) Taroang adalah SS bagian dari D.I. Kelara [6].

Saluran sekunder (SS) Taroang merupakan salah satu saluran sekunder yang berada pada daerah irigasi Kelara Kabupaten Jeneponto. Panjang total saluran sekunder Taroang adalah $9.633 \mathrm{~m}$ yang merupakan saluran dengan pasangan batu. Saat ini saluran sekunder Taroang mengairi $2.140 \mathrm{Ha}$ dengan debit sebesar 3,659 $\mathrm{m}^{3} /$ detik.

\section{Metode Penelitian}

Kebutuhan Air Irigasi (KAI) sebagian besar dicakupi dari air permukaan. KAI dipengaruhi oleh faktor klimatologi, kondisi tanah, koefisien tanaman, pola tanam, pasokan air yang diberikan, luas daerah irigasi, efisiensi irigasi, penggunaan kembali air drainase untuk irigasi, sistem golongan, jadwal tanam dan lain-lain.

$$
\mathrm{KAI}=\frac{\left(\mathrm{IR}+\mathrm{E}_{\mathrm{tc}}+\mathrm{P}+\mathrm{WLR}-\mathrm{Re}\right)}{\mathrm{IE}} \mathrm{x} \quad \mathrm{A} \ldots \ldots(1)
$$

Dengan $\mathrm{KAI}=$ kebutuhan air irigasi (liter/detik/ha); Etc $=$ kebutuhan air konsumtif $(\mathrm{mm} / \mathrm{hari})$; $\mathrm{IR}=$ kebutuhan air untuk penyiapan lahan $(\mathrm{mm} / \mathrm{hari})$; $\mathrm{WLR}=$ kebutuhan air untuk mengganti lapisan air ( $\mathrm{mm} /$ hari); $\mathrm{P}=$ perkolasi $(\mathrm{mm} /$ hari); $\mathrm{Re}=$ hujan efektif (mm/hari); IE= efisiensi irigasi (\%); $\mathrm{A}=$ luas areal irigasi (ha).

Penyiapan lahan (IR). Faktor-faktor penting yang menentukan besarnya kebutuhan air untuk IR adalah lamanya waktu yang dibutuhkan dalam menyelesaikan pekerjaan persiapan lahan. Selain itu, jumlah air yang diperlukan untuk penyiapan lahan sangat berpengaruh. Lamanya waktu IR tergantung pada tersedianya tenaga kerja dan ternak penghela atau traktor dalam penggarapan tanah. Kondisi sosial, serta budaya yang ada di daerah penanaman padi akan mempengaruhi lamanya waktu yang diperlukan untuk IR. Sebagai pedoman diambil jangka waktu 1,5 bulan untuk menyelesaikan IR diseluruh petak tersier. Bilamana untuk IR diperkirakan akan dipakai peralatan mesin secara luas, maka jangka waktu IR akan diambil 1 bulan. Untuk perhitungan kebutuhan irigasi selama penyiapan lahan, menggunakan metode yang ada pada KP-01 [7]. Metode tersebut didasarkan pada laju air konstan dalam
It/dt selama periode penyiapan lahan dan menghasilkan rumus:

$$
\mathrm{IR}=\mathrm{Me}^{\mathrm{k}} /\left(\mathrm{e}^{\mathrm{k}}-1\right)
$$

Dengan $\mathrm{IR}=$ Kebutuhan air penyiapan lahan (mm/hari) $\mathrm{M}=$ Kebutuhan air untuk mengganti kehilangan air akibat evaporasi dan perkolasi di sawah yang sudah dijenuhkan $(\mathrm{M}=\mathrm{Eo}+\mathrm{P}(\mathrm{mm} / \mathrm{hari}))$; $\mathrm{Eo}=$ Evaporasi air terbuka yang diambil 1,1 Eto selama penyiapan lahan $(\mathrm{mm} / \mathrm{hari}) ; \mathrm{P}=$ Perkolasi $(\mathrm{mm} / \mathrm{hari}) ; \mathrm{k}=$ $\mathrm{M} \times(\mathrm{T} / \mathrm{S}) ; \mathrm{T}=$ jangka waktu penyiapan lahan (30 hari); $\mathrm{S}=$ Kebutuhan air penjenuhan $(250 \mathrm{~mm}) ; \mathrm{e}=$ Bilangan Alam / Naperian Number (2,71828). Penggunaan konsumtif (Etc). Kebutuhan air untuk tanaman dilahan diartikan sebagai penggunaan konsumtif dengan memasukkan faktor koefisien tanaman (Kc). Jumlah air yang akan dipakai oleh tanaman untuk proses fotosistensis disebut penggunaan konsumtif (Aslan 1997). Etc dihitung dengan persamaan:

$$
\text { Etc }=\mathrm{Kc} . \text { Eto }
$$

Dengan Etc $=$ evapotranspirasi tanaman $(\mathrm{mm} / \mathrm{hari})$; Eto $=$ evapotranspirasi tanaman acuan $(\mathrm{mm} / \mathrm{hari})$; $\mathrm{Kc}=$ Koefisien tanaman. Evapotranspirasi (Eto) tanaman acuan adalah evapotranspirasi tanaman yang dijadikan acuan, yakni rerumputan pendek. Eto adalah kondisi evaporasi berdasarkan keadaan - keadaan meteorologi seperti: temperatur, sinar matahari (atau radiasi), kelembapan, angin [7]. Sifat-sifat tanah sangat mempengaruhi laju P. Pada tanah lempung berat dengan karakteristik pengolahan yang baik, laju $\mathrm{P}$ dapat mencapai 1 - $3 \mathrm{~mm} /$ hari. Laju P bisa lebih tinggi pada tanah yang lebih ringan. Guna menentukan laju $\mathrm{P}$, harus memperhitungkan tinggi muka air tanah. Meresapnya air melalui tanggul sawah dapat mengakibatkan perembesan [3]. WLR pada umumnya dilakukan setelah pemupukan dan menurut kebutuhan. Jika tidak ada penjadwalan semacam itu, penggantian sebanyak 2 kali, masingmasing $50 \mathrm{~mm}$ (atau $3,3 \mathrm{~mm} /$ hari selama setengah bulan) selama sebulan dan dua bulan setelah transplantasi.

$$
\operatorname{Re}=0,7 \times 1 / 2 \operatorname{Rs}(1 / 2 \text { dengan } T=5 \text { tahun }) .
$$


Efisiensi irigasi adalah perbandingan dari jumlah debit air irigasi yang dipakai dengan jumlah debit air irigasi yang dialirkan dan dinyatakan dalam persen (\%).

Efisiensi secara keseluruhan dihitung: Efisiensi jaringan tersier (80\%), efisiensi jaringan sekunder (80\%), efisiensi jaringan primer $(90 \%)$

Tabel 1. Harga-harga koefisien tanaman padi

\begin{tabular}{ccccc} 
Bulan & \multicolumn{2}{c}{ nedeco/prosida } & \multicolumn{2}{c}{ FAO } \\
& $\begin{array}{c}\text { Varietas } \\
\text { biasa }\end{array}$ & $\begin{array}{c}\text { Varietas } \\
\text { unggul }\end{array}$ & $\begin{array}{c}\text { Varietas } \\
\text { biasa }\end{array}$ & $\begin{array}{c}\text { Varietas } \\
\text { unggul }\end{array}$ \\
\hline 0,5 & 1,2 & 1,2 & 1,1 & 1,1 \\
1 & 1,2 & 1,27 & 1,1 & 1,1 \\
1,5 & 1,32 & 1,3 & 1,1 & 1,05 \\
2 & 1,4 & 1,3 & 1,1 & 1,05 \\
2,5 & 1,35 & 1,3 & 1,1 & 0,95 \\
3 & 1,24 & 0 & 1,05 & \\
3,5 & 1,12 & & 0,95 & \\
4 & 0 & & 0 & \\
\hline
\end{tabular}

Tabel 2. Harga-harga koefisien tanaman padi

\begin{tabular}{|c|c|c|c|c|c|c|c|c|c|c|c|c|c|c|c|}
\hline Tanaman & $\begin{array}{c}\text { Jangka } \\
\text { tumbuh/ } \\
\text { hari }\end{array}$ & $\begin{array}{c}1 / 2 \\
\text { bulan } \\
\text { No. }\end{array}$ & 1 & 2 & 3 & 4 & 5 & 6 & 7 & 8 & 9 & 10 & 11 & 12 & 13 \\
\hline Jagung & 80 & & 0,5 & 0,59 & 0,96 & 1,05 & 1,02 & 0,95 & & & & & & & \\
\hline kacang tanah & 130 & & 0,5 & 0,51 & 0,66 & 0,85 & 0,95 & 0,95 & 1 & 1 & 0,6 & 0,55 & & & \\
\hline Bawang & 70 & & 0,5 & 0,51 & 0,69 & 09 & 0,95 & & & & & & & & \\
\hline Buncis & 75 & & 0,5 & 0,64 & 0,89 & 0.95 & 0,88 & & & & & & & & \\
\hline Kapas & 195 & & 0,5 & 0,5 & 0,58 & 0,75 & 0,91 & 1,04 & 1,1 & 1,1 & 1,1 & 0,78 & 0,65 & 0,7 & 0,7 \\
\hline
\end{tabular}

\section{A. Waktu dan Lokasi Penelitian}

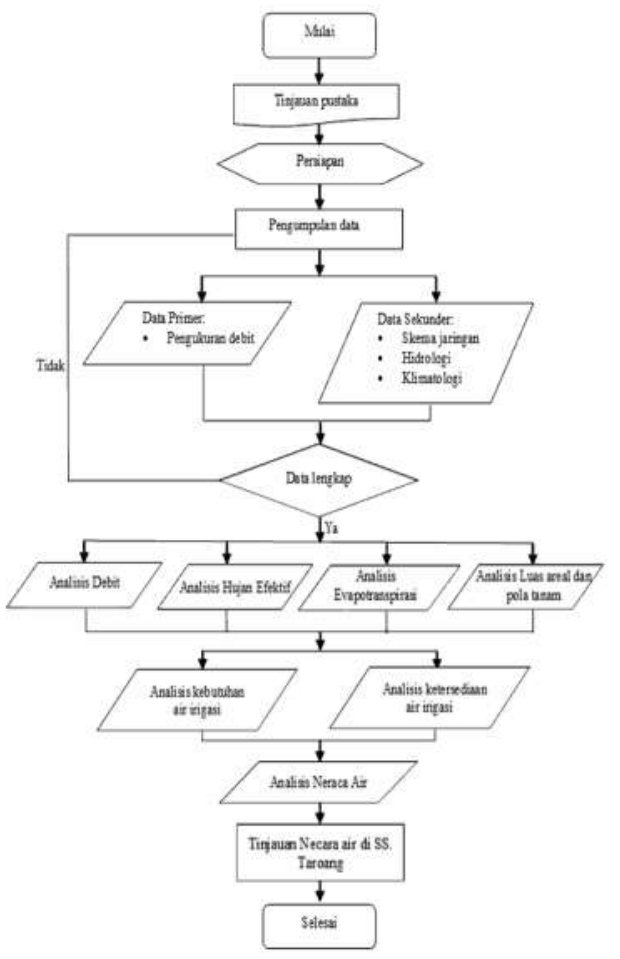

Gambar 2. Diagram Alir Penelitian
Penelitian ini berlangsung selama enam bulan mulaidari bulan Februari sampai bulan Juli 2018 dengan lokasi penelitian terletak di Kecamatan Kelara, Kabupaten Jeneponto, Provinsi Sulawesi Selatan [8].

\section{B. Pengumpulan Data}

Data Primer yang digunakan adalah pengukuran langsung debit aliran di SS di daerah layanan irigasi (SS Taroang) dan interview/wawancara dengan orang yang terkait dengan masalah ini (Petani, Kelompok tani, serta orang yang terlibat dalam pengoperasian DI Kelara).

Analisa debit sungai dan penentuan debit andalan merupakan faktor penting dalam penentuan ketersediaan air irigasi. Debit andalan didefinisikan sebagai debit minimum rata-rata mingguan atau bulanan. Debit minimum rata-rata minggunan atau tengah bulanan ratarata untuk kemungkinan tak terpenuhi 20\%. Debit andalan yang dihitung dengan cara ini tidak sepenuhnya dapat dipakai untuk irigasi karena aliran sungai yang dielakkan mungkin bervariasi sekitar harga rata-rata mingguan atau tengah bulanan.. Debit saluran. dalam sebuah saluran irigasi, mengetahui debit aliran dalam sebuah saluran irigasi adalah sangat penting. Salah satu metode dalam melakukan pengukuran debit air di saluran adalah metode pengukuran debit dengan cara apung (Float Area methode). Kecepatan aliran (V) ditetapkan berdasarkan kecepatan pelampung (V). Pengukuran kecepatan aliran air merupakan salah satu bagian yang sangat penting. Karena penentuan kecepatan di sejumlah di suatu penampang memungkikan penentuan besarnya debit, sehingga dalam hal ini pengukuran kecepatan merupakan suatu fase yang penting dalam pengukuran aliran (Iqbal and Faisal 2018), sedangkan untuk Luas penampang (A) ditetapkan berdasarkan pengukuran lebar saluran (L) dan tinggi muka air disaluran (H). Sehingga didapatkan nilai debit (Q). Dalam perhitungan neraca air, kebutuhan pengambilan yang dihasilkan untuk pola tanam yang akan dipakai dibandingkan dengan debit yang lewat disaluran untuk area irigasi yang akan dialiri [7]. Perhitungan ini untuk mengecek apakah air yang tersedia cukup memadai untuk memenuhi kebutuhan air irigasi di daerah tinjauan.

Data sekunder yang digunakan adalah peta topografi, data hidrolimatologi dari BMKG dan PU. 


\section{Teknik Analisis Data}

Data yang ada selanjutnya diolah dengan rumus sesuai. Hasil dari suatu pengolahan data digunakan untuk menganalisis Kebutuhan air Irigasi (KAI). Datadata yang diperoleh dari hasil penelitian, dianalisis dengan menggunakan Metode simulasi F.J. Mock atau Nreca. Untuk menganalisa data iklim dengan menggunakan Metode Penman Modifikasi FAO.

\section{Hasil dan Pembahasan}

\section{A. Penggunaan konsumtif (Etc)}

Dalam menentukan kebutuhan air irigasi, perhitungan Eto sangat besar pengaruhnya [9]-[13], [4]. Data-data yang diperlukan untuk perhitungan Eto meliputi: data suhu harian maksimum dan minimum rata, data kelembaban relatif rata-rata, data kecepatan angin, dan data lama penyinaran matahari [7]. Data tersebut diperoleh dari stasiun Klimatologi Gantinga yang terletak di daerah layanan irigasi 5036 $28^{\prime \prime}$ LS $119^{\circ} 45^{\prime}$ 53" BT.

Tabel 3. Data Klimatologi Rata-Rata Stasiun Gantinga

\begin{tabular}{|c|c|c|c|c|c|c|c|c|c|}
\hline urain & Satuar Jan & Feb Mar Apr & Mei & Jun & Jul & Agst & Sep & Okt & Nop Des \\
\hline suhu $(t)$ & & $\begin{array}{lll}23,7 & 23,8 & 24,28\end{array}$ & 24,25 & 23,65 & 23,3 & 23,7 & 24,7 & 25,2 & $25,2 \quad 24,7$ \\
\hline Sinar Matahari (n) & Jam 3,69 & $\begin{array}{lll}5,18 & 5,36 & 4,74\end{array}$ & 5,49 & 4,62 & 4,34 & 5,4 & 5,89 & 5,15 & $5,15 \quad 2,38$ \\
\hline Kelembaban (Rdh) & 79 & $\begin{array}{lll}77,6 & 79,8 & 77\end{array}$ & 78,75 & 68,99 & 64,3 & 62,54 & & 62,3 & $62 \quad 61,5$ \\
\hline Kecepatan angin (u) & $\mathrm{m} / \mathrm{dt} \quad 2,16$ & $\begin{array}{lll}1,06 & 1,91 & 0,433 \\
\end{array}$ & 0,439 & 0,678 & 0,8 & 1,2802 & & 1,41 & $1,03 \quad 1,32$ \\
\hline
\end{tabular}

Dengan Eto $=$ Penguapan dalam ( $\mathrm{mm} / \mathrm{hari})$; $\mathrm{Pa}=$ Tekanan uap jenuh pada suhu rata harian dalam $\mathrm{mmHg} ; \mathrm{Pu}=$ Tekanan uap sebenamya dalam $\mathrm{mmHg}$; $\mathrm{U} 2=$ Kecepatan angin pada ketinggian $2 \mathrm{~m}$ dalam mile/hari, sehingga bentuk U2 dalam $\mathrm{m} / \mathrm{dt}$ masih harus dikalikan dengan $24 \times 60 \times 60 \times 1600$.

Tabel 4. Data Klimatologi Rata-Rata Stasiun Gantinga

Jan Feb Mar Apr Mei Jun Jul Agst Sep Okt Nop Des \begin{tabular}{llllllllllllll} 
ET0 & mm $/$ hari & 4,67 & 4,78 & 4,64 & 3,48 & 3,38 & 3,32 & 3,47 & 4,7 & 5,64 & 5,7 & 5,51 & 4,74 \\
\hline
\end{tabular}

Berdasarkan data tersebut, maka Eto dapat dihitung dengan persamaan [14]:

$$
\text { Eto }=0,35(\mathrm{~Pa}-\mathrm{Pu})(1+\mathrm{U} 2 / 100)(1)
$$

Penyiapan lahan untuk tanaman padi dimulai pada November 1 (sesuai pola tanam) dan dihitung dengan persamaan:
$\mathrm{IR}=\mathrm{Mek} /(\mathrm{ek}-1)$

Tabel 5. IR rata-rata bulanan

\begin{tabular}{c|c|c|c|c|c|c|c|c|c|c|c|c} 
Bulan & Jan. & Peb. & Mar. & Apr. & Mei & Jun. & Jul. & Agt. & Sep. & Okt. & Nop. & Des. \\
\hline $\mathbb{R}$ & 12.40 & 12.48 & 12.38 & 11.59 & 11.52 & 11.48 & 11.57 & 12.43 & 13.10 & 13.14 & 12.74 & 12.45 \\
\hline
\end{tabular}

Pada daerah irigasi Kelara umumnya bertanah lempung sehingga digunakan nilai Perkolasi $2 \mathrm{~mm} / \mathrm{hari}$. Berdasarkan Standar Kriteria Perencanaan Bagian Jaringan Irigasi [7], besarnya kebutuhan air yang digunakan untuk penggantian lapisan air adalah 3,3 $\mathrm{mm} /$ hari.

Curah hujan efektif irigasi tanaman padi diambil 70\% sedangkan untuk palawija diambil $50 \%$ dari curah hujan rata-rata tengah bulanan dengan kemungkinan tak terpenuhi 20\% (curah hujan andalan R80). Curah hujan andalan $\left(\mathrm{R}_{80}\right)$ untuk D.I. Kelara dihitung dari curah hujan setengah bulanan rata-rata dari 4 stasiun hujan disekitarnya, yaitu: Sta. Paitana, Sta. Tanrang, Sta. Taroang, Sta. Gantinga.

Tabel 6. Stasiun Curah Hujan

\begin{tabular}{|c|c|c|c|c|c|}
\hline \multirow{2}{*}{ No } & \multirow{2}{*}{ Stasium } & \multicolumn{2}{|c|}{ koordinat } & \multirow[b]{2}{*}{ Tahum } & \multirow{2}{*}{ Ket. } \\
\hline & & LS & BI & & \\
\hline 1 & BT. Rappo (Tarcang) & $5^{\circ} 36^{\prime} 00^{\prime \prime}$ & $11^{\circ} 51^{\circ} 00^{7 \%}$ & $1975-2016$ & $\begin{array}{c}\text { Daerah Layanan } \\
\text { Inigasi }\end{array}$ \\
\hline 2 & Paitana & $5^{\circ} 31^{\prime} 27^{\prime \prime}$ & $119^{\circ} 49^{\prime} 00^{\prime \prime}$ & $1975-2015$ & $\begin{array}{c}\text { Dacrah Layanan } \\
\text { Inigasi }\end{array}$ \\
\hline 3 & Pamisorang & $5^{\circ} 38^{\prime} 12^{\prime \prime}$ & $119^{\circ} 47^{\prime} 32^{\prime \prime}$ & $1975-2016$ & $\begin{array}{c}\text { Daerah Layanan } \\
\text { Ingasi }\end{array}$ \\
\hline 4 & Gantinga & $5^{\circ} 36^{\prime} 00^{\prime \prime}$ & $119^{\circ} 47^{\prime} 00^{\prime \prime}$ & $1975-2015$ & $\begin{array}{c}\text { Dae rah Layanan } \\
\text { Inigasi }\end{array}$ \\
\hline
\end{tabular}

Curah hujan andalan $\left(\mathrm{R}_{80}\right)$ diambil dari data hujan 15 harian yang terurut, dengan probabilitas terpenuhi $80 \%$. Efisiensi irigasi untuk SS Taroang diambil $80 \%$. Dan SS Taroang mengairi areal seluas $2.140 \mathrm{Ha}$.

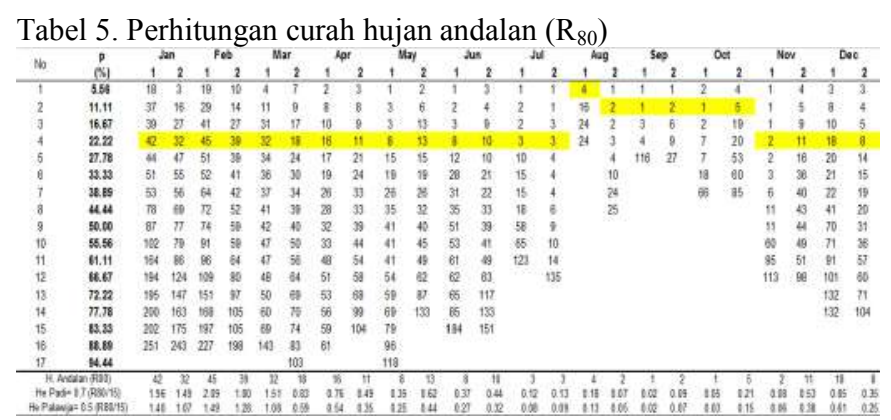


Berdasarkan tabel 5 dijelaskan bahwa hujan andalan (R80) diambil dari hujan $1 / 2$ bulanan dengan probabilitas terpenuhi $80 \%$ adalah $42,32,45,39,32,18$, $16,11,8,13,8,10,3,3,4,2,1,2,1,5,2,11,18,8$.

\section{B. Ketersediaan Air Irigasi}

Perhitungan debit di SS Taroang dilaksanakan dengan menggunakan metode apung (Float Area methode) [2]. Hasil pengambilan data langsung dilapangan ditampilkan pada tabel berikut.

Tabel 7. Tinggi muka air $(\mathrm{H})$

\begin{tabular}{ccccc}
\hline \multirow{2}{*}{ Perco baan } & \multicolumn{3}{c}{ Tinggi muka air $(\mathbf{m})$} & \multicolumn{2}{c}{ Tinggi rata-rata (m) } \\
& $\mathbf{H}_{\mathbf{1}}$ & $\mathbf{H}_{\mathbf{2}}$ & $\mathbf{H}_{\mathbf{3}}$ & \\
\hline 1 & 0.21 & 0.23 & 0.203 & 0.21 \\
2 & 0.245 & 0.255 & 0.24 & 0.25 \\
3 & 0.293 & 0.29 & 0.285 & 0.29 \\
4 & 0.33 & 0.34 & 0.32 & 0.33 \\
\hline
\end{tabular}

Bentuk penampang pada S.S. Taroang yaitu trapesium dimana perbandingan kemiringan saluran yaitu $1: 1$. Lebar dasar saluran yaitu 1,5 $\mathrm{m}$ sehinga luas penampang basah (A) adalah:

Tabel 8. Luas penampang basah (A)

\begin{tabular}{ccccc} 
Percobaan & bentuk penampang & H rata-rata (m) & Lebar Dasar (m) & A (m $\left.\mathbf{m}^{2}\right)$ \\
\hline 1 & & 0.21 & 1.5 & 0.37 \\
2 & \multirow{2}{*}{ trapesium } & 0.25 & 1.5 & 0.43 \\
3 & & 0.29 & 1.5 & 0.52 \\
4 & & 0.33 & 1.5 & 0.60 \\
\hline
\end{tabular}

Tabel 9. Waktu pengukuran (detik)

\begin{tabular}{ccccc}
\hline \multirow{2}{*}{ Percobaan } & \multicolumn{2}{c}{ Waktu Pengukuran (de tik) } & Waktu rata-rata (detik) \\
& $\mathrm{T}_{\mathbf{1}}$ & $\mathbf{T}_{\mathbf{2}}$ & $\mathbf{T}_{\mathbf{3}}$ & \\
\hline 1 & 23.2 & 25.7 & 22.3 & 23.73 \\
2 & 20.1 & 22.2 & 21.3 & 21.20 \\
3 & 16.1 & 19 & 17.9 & 17.67 \\
1 & 15 & 16.3 & 16.1 & 15.80 \\
\hline
\end{tabular}

Tabel 10. Kecepatan pelampung (V)

\begin{tabular}{cccc}
\hline Percobaan & Panjang saluran (m) & wak tu (de tik) & Kecepatan (m/s) \\
\hline 1 & 10 & 23.73 & 0.42 \\
2 & 10 & 21.20 & 0.47 \\
3 & 10 & 17.67 & 0.57 \\
4 & 10 & 15.80 & 0.63 \\
\hline
\end{tabular}

Debit yang masuk ke S.S. Taroang adalah $\mathrm{Q}=\mathrm{VAk} ; \mathrm{Q}=$ $0,42 \times 0,37 \times 0,80=0,12 \mathrm{~m} 3 / \mathrm{dtk}$. Jika ditabelkan maka debit SS Taroang adalah:

\begin{tabular}{|c|c|c|c|c|}
\hline Percobaan & Luas Penampang $(\mathrm{m})$ & Kecepatan $(\mathrm{m} / \mathrm{s})$ & $\begin{array}{c}\text { koefisien } \\
\text { pelampung }\end{array}$ & Debit ( $\left.\mathrm{m}^{3} / \mathrm{dtk}\right)$ \\
\hline 1 & 0.37 & 0.42 & 0.80 & 0.12 \\
\hline 2 & 0.43 & 0.47 & 0.80 & 0.16 \\
\hline 3 & 0.52 & 0.57 & 0.80 & 0.23 \\
\hline 4 & 0.60 & 0.63 & 0.80 & 0.31 \\
\hline
\end{tabular}

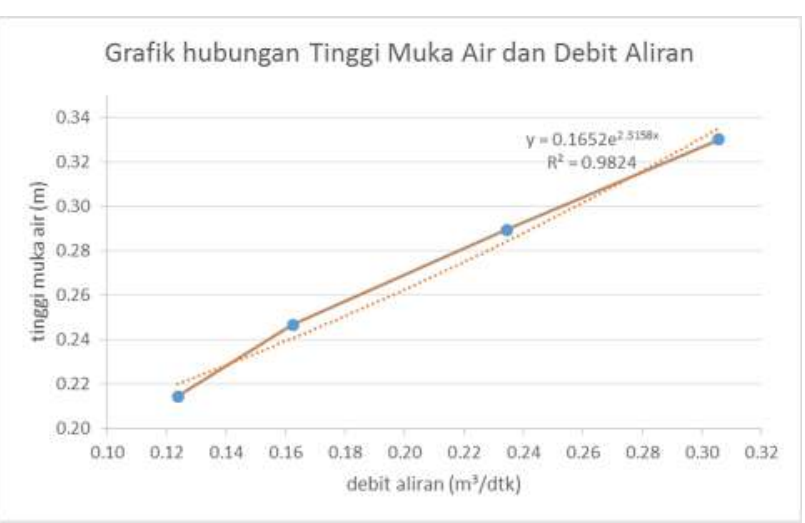

Gambar 3. Grafik Hubungan Debit dan Tinggi muka Air.

Tabel 11. Kebutuhan air di SS Taroang (2140 ha)

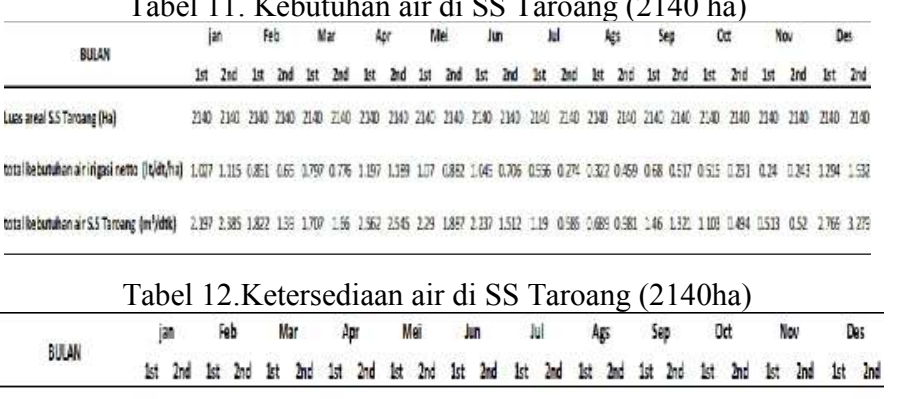

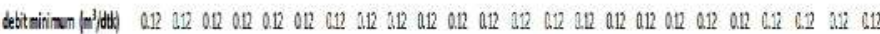

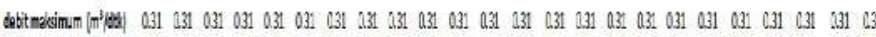

GRAFIK HUBUNGAN ANTARA KEBUTUHAN \& KETERSEDIAAN AIR DI S.S TAROANG (2140 HA)

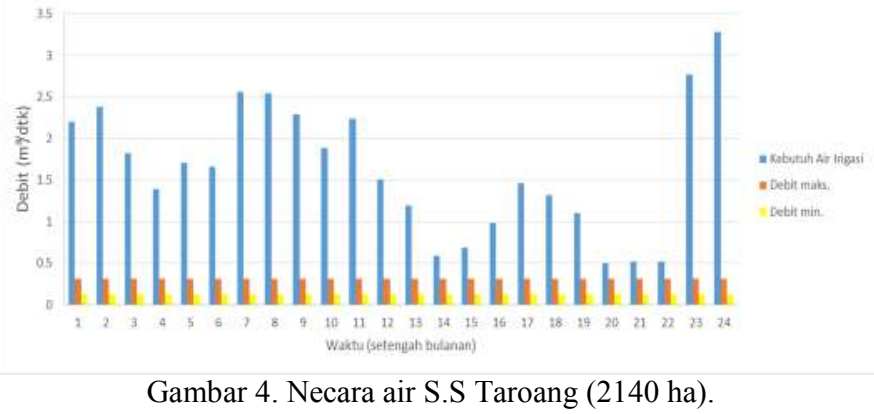

Pada gambar 4, terlihat bahwa rata-rata kebutuhan air SS. Taroang setengah bulanan adalah 1,629 m3/detik. Terlihat pula rata-rata ketersediaan air irigasi adalah 
sebesar 0,215 $\mathrm{m} 3 /$ detik. Sehingga ada selisih antara kebutuhan air dengan ketersediaan air sebesar 1,414 m3detik.

\section{Kesimpulan}

Kebutuhan Air Irigasi (KAI) pada SS Taroang yang memiliki luas area $2.140 \mathrm{Ha}$ untuk dialiri selama setahun yaitu 39,11 m3/detik. Ketersediaan air irigasi pada SS Taroang berdasarkan hasil pengukuran debit yang masuk ke saluran didapatkan debit minimum sebesar 0,12 $\mathrm{m} 3 /$ detik. Sedangkan debit maksimum yang masuk kesaluran sebesar 0,31 m3/detik. Dari hasil analisa neraca air diketahui bahwa, ketersediaan air yang masuk ke SS Taroang tidak mencukupi untuk mengairi areal irigasi seluas $2.140 \mathrm{Ha}$. Untuk menanggulangi hal tersebut maka harus mempertimbangkan 3 pilihan: 1 . Luas daerah irigasi dikurangi; 2. Melakukan modifikasi dalam pola tanam; 3. Melakukan rotasi teknis golongan.

\section{Ucapan Terima Kasih}

Ucapan terima kasih diberikan kepada Dinas PSDA Propinsi Sulawesi Selatan dan Balai Besar Wilayah Sungai Pompengan Jeneberang (BBWSPJ) yang memberikan data dan peta yang di gunakan untuk analisis dalam tulisan ini.

\section{Daftar Pustaka}

[1] A. Fajar et al., "Pemberian Air Dalam Pengelolaan Air Irigasi Efficiency Of Pipe Irrigation System To Identify The Feasibility", pp. 33-42, 2016.
[2] A. R. Suleman, M. T. Iqbal, E. Bahrul, and M. I. Ashari, "Identification of damaging assets irrigation levels of the tertiary to the area Bissua based on geographic information system (GIS)," ARPN J. Eng. Appl. Sci., vol. 11, no. 9, 2016.

[3] A. Ansori et al., "Evaluasi Kinerja Daerah Irigasi," vol. I, no. 1, pp. 1-10, 2013.

[4] A. P. Savva and K. Frenken, "Crop Water Requirements and Irrigation Scheduling," Food Agric. Organ., p. 132, 2002.

[5] K. Jembrana, "Efektivitas pengelolaan irigasi dengan sumur pompa di kecamatan negara, kabupaten jembrana," 2015.

[6] S. . T. Puntodewo, A.; Dewi, "Aplikasi SIG dalam Pengelolaan SDA Part 5,”p. viii, 127p.; ill., 2003.

[7] Departemen Pekerjaan Umum, "Standar Perencanaan Irigasi : Kriteria Perancangan Jaringan Irigasi(KP-01)," pp. 14-38, 1986.

[8] Y. Arafat, M. Saleh Pallu, F. Maricar, and R. T. Lopa, "Morphology evolution of lower Jeneberang River, Indonesia," Int. J. Earth Sci. Eng., vol. 8, no. 5, pp. 20112016, 2015.

[9] B. Ashraf et al., "Quantifying Anthropogenic Stress on Groundwater Resources," Sci. Rep., vol. 7, no. 1, pp. 1-9, 2017.

[10] T. Yuliawati, T. K. Manik, and R. A. B. Rosadi, "Pendugaan Kebutuhan Air Tanaman Dan Nilai Koefisien Tanaman (Kc) Kedelai (Glycine Max (L) Merril ) Varietas Tanggamus Dengan Metode Lysimeter," J. Tek. Pertan. Lampung, vol. 3, no. 3, pp. 233-238, 2014.

[11] D. L. Martin and J. R. Gilley, "Irrigation Water Requirements," Part 623 Natl. Eng. Handb., no. September 1993, p. 284, 1993.

[12] S. L. Bithel and S. Smith, "The Method for Estimating Crop Irrigation Volumes for the Tindall Limestone Aquifer, Katherine, Water Allocation Plan.," North. Territ. Gov. Aust., 2011.

[13] W. R. Kneebone, C. F. Mancino, and D. M. Kopec, "Water Requirements and Irrigation," Turfgrass, pp. 441-472, 1992.

[14] M. B. Defersha and A. M. Melesse, "Effect of rainfall intensity, slope and antecedent moisture content on sediment concentration and sediment enrichment ratio," Catena, vol. 90, pp. 47-52, 2012. 